\title{
Exploring the Training Needs for Climate Change and Sustainable Energy Consumption in the Case of Public Local Authorities
}

\author{
IUDIT BERE - SEMEREDI \\ Politehnica University of Timisoara, Romania \\ iudit.bere-semeredi@student.upt.ro \\ ANCA DRAGHICI \\ Politehnica University of Timisoara, Romania \\ anca.draghici@upt.ro \\ GABRIELA FISTIS \\ DEnKstat T Romania Timisoara, Romania \\ gabriela.fistis@denkstatt.ro
}

Climate change (cc) is a new reality that impacts urban life and costly impacts on cities' infrastructure, services, housing and human health. Cities are the agents and the places of change in addressing climate change, but sometimes there remains a concerned lack of powerful evidence for their effectiveness and capacity to accomplish this role. This paper therefore attempts to highlight a possible way to approach change at organizational, team and individual levels through training and leadership, to overcome barriers, for a better understanding of how the public administration can be more performant. The questionnaire-based survey results expose the actual status of understanding climate change, energy and sustainability issues and stress the need for trainings for individuals and teams that are implementing energy and climate strategies in the all mentioned topics. The survey also collects information regarding the main learning sources and the role of leadership for supporting a learning environment.

Key words: climate, change, energy, management, training, leadership

(cc) BY-SA https://doi.org/10.26493/1854-4231.15.87-97

\section{Introduction}

Energy efficiency ( $\mathrm{EE}$ ) is one of the five key dimensions of the Energy Union. The importance of $\mathrm{E} E$ was underlined by the ambitious Paris Agreement, the energy saving target until 2030 being established by the Climate and Energy Framework to $27 \%$ by 2030. In this context, 
the transition to a low-carbon economy can only be achieved through investments in $\mathrm{EE}$. In order to make $\mathrm{EE}$ investments possible in a much easier way, the creation of energy policies is essential. One of the central components of the Eu's energy efficiency policy is represented by the building sector. Statistic shows that buildings sector is responsible for $40 \%$ of final energy consumption, $36 \%$ of greenhouse gas emissions (GHG) and almost $75 \%$ of buildings are not energy efficient. Improving the $\mathrm{E} \mathrm{E}$ of the existing building is essential in order to meet the national targets in this field, but also to achieve the objectives on the climate change, for a low-carbon economy until 2050 (United Nations 2015; European Commission 2011). In the past years, public institutions and local public companies have dedicated limited attention to cc and sustainable development. The recent years $\mathrm{EE}$ investments, mitigation and adaptation measures were recognized as public management priorities. Despite the local authorities' engagement, there are several constraints which consist of institutional rigidity, financial constrictions, organization employee, lake of knowledge, skills and technical capacity, all limiting the implementation of energy and climate strategies and achieving the established targets (European Commission 2019).

The concept of sustainable development of the cities can be described by its four pillars: economic development, social development, environmental management and efficient and effective urban governance. Building or rethinking urban areas upon the four pillars is a challenge for many cities. Recent practices and studies have shown that the awareness of the population as consumers and of employees of some organizations on climate change is quite low. The concept of sustainability, climate change mitigation and adaptation, or vulnerability and risk to cc are quite poorly known, and pro-climate behaviour and practices are also virtually unknown. Increasing awareness among citizens and public employee is an important factor in streamlining $\mathrm{E} \mathrm{E}$, climate action and measures. The previous research performed at the population level, regarding climate change - mitigation/adaptation, has led to the conclusion that these aspects, although considered important, are not followed by consistent actions, and the cohesion around actions for climate protection is still weak (European Commission 2019).

From the specialty literature in the field of sustainability management, it has been pointed out that, there are methods and tools that can guide organizations in their development and reorientation towards sustainability and climate protection, through an analysis of their present situation and by applying measures of improvement. If 
until recently the Triple Bottom Line approach, which was initially addressed by John Elkington in 1994 (3P - People-Planet-Profit, associated with sustainability dimensions) was frequently used, especially among companies, in the future, in the local authorities (LAS) we must pay attention to issues related to sustainability, by approaching of the Quadruple Bottom Line type (QBL) (Environmental, Social, Economic and Governance).

Measuring sustainability by using indicators related to the four pillars of the QBL method will be able to provide an overview. Sustainability and resilience plans will be a must in the future, to achieve good governance and improve the operational efficiency. Sustainability plans are designed to prepare the city for and respond to future challenges and opportunities in a sustainable and coordinated manner (Alibašić 2017).

To remain within the area of operational excellence, the LAs need to improve in a constant and systematic way their activities. In this context, organizational learning could be a strategic tool of the modern management. Learning, from this perspective is not only about improving knowledge and skills but is also a path to build a successful, flexible and dynamic organization.

The practical reality shows that public servants are sometimes under pressure to 'do more with less,' often without adequate training. Public employees and decision-making training are sometimes too little or too late. Lack of skills, time and workload demands, qualifications and training appear to be one of the principal reasons of LAS underperformance. Professional development is relevant for both employees and organizations. The researches performed in the field shows that professional development is directly related to the dayto-day activities of employees and should be part of a deeper process of continuous learning (Guskey 2003), both formal and informal learning. Professional development is associated with the continuous process of enrichment and maturation of the knowledge, skills and attitudes that are acquired throughout the course of the work activity, through training, formal and informal learning process at the workplace. Similar considerations and an inspirational training need assessment in the field of sustainable development topics are presented by (Draghici et al. 2015). The relationship between learning at work, everyday learning and formal training was already analysed in the literature (Dobos 2014; Stewart 2014). Formal and informal learning in the workplace context could be developed in various forms, being related to the development of human capital (Noe, Clarke, and Klein 2014). The professional development pro- 
cess consists of an assemble of personal experience that form and define the learning throughout the career development (Korthagen 2017).

Thus, in the context of the present article, there will be presented a research approach for the identification and characterization of the training needs for climate change and sustainable energy consumption in the case of the employees from public LAs. The importance of this topic arises from the actual situation induced by the cc to city management and the high pressure that boost public servants and other employees from public organizations to elaborate and urgent implement measures for risk mitigation. The paper structure consists of the following chapters: (1) presentation of the research methodology; (2) comments and debate on the research results about the training needs for climate change and sustainable energy consumption in the case of the employees from public LAs; (3) conclusions.

\section{Research Context}

Since June 2019, the Municipality of Timisoara is implementing the project called 'Smart and Sustainable Energy Consumption' acronym SASEC, e-MS RORS-300, launched under the Interreg IPA Cross-border Cooperation Program Romania-Serbia. The partnership consists of two LAs, from both side of the border - City of Zrenjanin and Municipality of Timisoara, the Regional Agency for SocioEconomic Development - Banat and the Romanian Sustainable Energy Cluster - ROSEnC. The project activities were circumscribed to the concepts of sustainability, responsible energy consumption, energy efficiency, administrative capacity development, promotion of a cross-border network for education and research on environmental resources and awareness raising about importance of energy savings and the potential of renewable energy sources (RES).

One of the project goals is to develop a consistent training material and to perform a three-day training program, targeting the public servants and specialist from both cities and to organize a round table with specialists and local key-stakeholders. The trainees - public servants, specialists from the local administration, administrators of public buildings, forming the target groups are expected to attain theoretical knowledge and skills to transpose them into the daily activity. The expected result of these activities is the successful implementation of the Sustainable Energy Action Plan (SEAP) and the future Sustainable Energy and Climate Action Plan (SECAP) that will be developed during 2020 . 


\section{The Research Methodology}

Designing relevant training materials and providing the most suitable training services can only be achieved after completing an essential stage, that of investigating the need for training. Aiming to identify the status of knowledge and the interest for different topics, a questionnaire was elaborated, adapted to the city hall level and the specific municipal responsibilities, establish by law. The questionnaire was aimed at two main target groups, civil servants from Timisoara Municipality and specialist from local public service provider companies, in executive and decision-making positions.

The research method was based on a designed questionnaire. The questionnaire was conducted on a sample of 75 civil servants, using the survey method of sociological research; it was distributed by the project manager to the main departments from the city hall and sent by e-mail to the local companies and institutions, following to the invitation to the training. The survey was conducted in February 2020, with the participation of 67 valid respondents, representing a response rate of $89.34 \%$.

The survey was run in the City Hall of Timisoara and was wellaccepted by all participants. Also, the survey was voluntary and anonymous, the respondents being asked only for data on gender, age, level of education, position and profession. The survey covered the actual status of knowledge regarding cc, sustainable energy consumption and $\mathrm{EE}$ and proposed twelve topics to be appreciated in different degrees of relevance/interest by the potential trainees. The survey sought to capture aspects of the usefulness of the information for personal growth in activity in the workplace but also in private life. The usual sources of information and learning, the materials and the methods of training, but also the ways in which the knowledge is transmitted in the organization were investigated. Assessing the degree to which the leaders are involved in looking for opportunities for learning and support learning and desire their support for a sustainable organization has also been subject to investigation.

The research group demography, educational background and position in the organization are shown in tables 1 and 2. From the total of 67 respondents, 59 are employees of the local government institutions and 8 are of local public service companies. The proportion of respondents under gender, that of $61 \%$ women and $39 \%$ men, is close to that of the institution. 80.6\% participants held an executive function, while $19.4 \%$ held a managerial function. All participant has high education, $52.24 \%$ bachelor's degree, $40.3 \%$ master's degree and 
TABLE 1 The Research Group Demography

\begin{tabular}{lrr}
\hline Age groups & Males (\%) & Females (\%) \\
\hline $25-35$ & 4.47 & 17.91 \\
$35-49$ & 16.41 & 16.41 \\
$>45$ & 17.65 & 26.86 \\
\hline
\end{tabular}

TABLE 2 The Research Group educational Background and Position in the Organization

\begin{tabular}{llr}
\hline Item & Category & Number \\
\hline Position & Executive position & 54 \\
& Decision-making position & 13 \\
\hline Level of studies & Bachelor's Degree & 35 \\
& Master's Degree & 27 \\
& Doctoral Degree & 5 \\
\hline Professions & Engineers & 33 \\
& Economists & 9 \\
& Legal Advisors & 5 \\
& Other professions & 20 \\
\hline
\end{tabular}

7.47\% PhD. From the professional sphere, the great majority of the respondents are engineers, economists and legal advisors, but also architects, communication specialists, and psychologists - included in the category of 'other profession.' The age group analysis reveals clearly that respondent group over 45 is larger compared to that $35^{-}$ 45 years group, the latter being more numerous than the one under 25 years. The developed questionnaire proposed to the respondent's relevant topics in the wider area of sustainability, energy efficiency, sustainable energy consumption and climate change. Respondents had the opportunity to appreciate nine topics, using a Likert scale of 5 points.

\section{Research Results}

Investigating the current state of knowledge in the domains and subdomains indicated (table 3), highlights the need for introductive courses in some domains but also of specialization courses in others. At first glance, it is encouraging to find in the area of 'Moderate level of knowledge' a high number of respondents (between 35\% and 53\%), but depending on the field of activity in which some public servants activate, this result may be unsatisfactory. In addition, noteworthy is the fact that 'circular economy' is unknown or just little-known field for $14.94 \%$, respectively $22.39 \%$ respondents. 
TABLE 3 Research Results: The Assessment on Actual Knowledge Level

\begin{tabular}{lrrrrr}
\hline Topics under survey & $(1)$ & $(2)$ & $(3)$ & $(4)$ & $(5)$ \\
\hline GHG emissions reduction & 4.48 & 13.43 & 53.73 & 22.39 & 5.97 \\
Climate change adaptation & 2.99 & 19.40 & 53.73 & 17.91 & 5.97 \\
Sustainability concept & 4.48 & 19.40 & 43.28 & 26.87 & 5.97 \\
Water consumption & 0.00 & 8.96 & 35.82 & 44.78 & 10.44 \\
Energy consumption & 0.00 & 7.46 & 37.31 & 41.79 & 13.44 \\
Waste management & 1.49 & 5.97 & 38.81 & 43.28 & 10.44 \\
Circular economy & 14.94 & 22.39 & 37.31 & 16.42 & 8.96 \\
Energy efficiency & 2.99 & 22.39 & 37.31 & 28.36 & 8.96 \\
\hline
\end{tabular}

Notes Percentage. Column headings are as follows: (1) no knowledge, (2) low level of knowledge, (3) moderate level of knowledge, (4) strong level of knowledge, (5) very strong level of knowledge.

TABLE 4 Research Results: The Analysis of the Training Needs

\begin{tabular}{lrrrrrr}
\hline Topics under survey & $(1)$ & $(2)$ & $(3)$ & $(4)$ & $(5)$ & $(6)$ \\
\hline Legal framework - EE & 1.49 & 7.46 & 38.81 & 31.34 & 20.90 & 52.24 \\
Energy consumption in buildings & 0.00 & 5.97 & 40.30 & 41.79 & 11.94 & 53.73 \\
RES in public buildings & 0.00 & 5.97 & 37.31 & 31.34 & 25.37 & 56.71 \\
Building energy performance & 0.00 & 5.97 & 32.84 & 41.79 & 19.40 & 61.19 \\
Climate change & 0.00 & 5.97 & 29.85 & 40.30 & 23.88 & 64.18 \\
GHG inventory and monitoring & 0.00 & 7.46 & 38.81 & 31.34 & 22.39 & 53.73 \\
Sustainable development goals & 1.49 & 10.45 & 35.82 & 32.84 & 19.40 & 52.24 \\
Transport sector & 0.00 & 5.97 & 37.31 & 44.78 & 11.94 & 56.72 \\
Water management & 0.00 & 5.97 & 28.36 & 52.24 & 13.43 & 65.67 \\
Waste management & 0.00 & 4.48 & 40.30 & 31.34 & 23.88 & 55.22 \\
Good practices - EE in buildings & 1.49 & 5.97 & 29.85 & 38.81 & 23.88 & 62.69 \\
Nearly zero-energy buildings & 8.96 & 20.90 & 29.85 & 23.88 & 26.87 & 50.75 \\
\hline
\end{tabular}

Notes Percentage. Column headings are as follows: (1) no need, (2) low level of need, (3) moderate need, (4) strong need, (5) very strong need, (6) moderate, strong, very strong need.

In table 4 there are summarized the research results for identifying the training needs related to the chosen topics that has been selected for the survey. According to the respondents' opinions, they have moderate, strong and very strong needs expressed for the following topics: water management, climate change, good practices related to $\mathrm{EE}$ for the buildings sector and building energy performance (the percent of the responses are over $60 \%$ for all these topics). cc and sustainability are areas of great relevance that will require additional attention, including from the point of view of the need for training, these being indicated in a remarkable percentage as 'Low 
TABLE 5 The Sources of Professional Information and Learning

\begin{tabular}{lr}
\hline Source & Number \\
\hline Specialty literature & 36 \\
Legislation & 25 \\
Participation to the projects & 24 \\
Workshops & 21 \\
Conferences & 21 \\
Trainings & 15 \\
Other & 7 \\
\hline
\end{tabular}

NотеS Multiple answers were possible.

TABLE 6 Results on the Most Relevant Training Materials and Methods and Information Transfer

\begin{tabular}{lr}
\hline Sources of professional information and learning & Number \\
\hline Debates on real cases or hypothetical scenarios & 45 \\
Video presentation materials - presentation of best practices & 40 \\
Presentations - concept, terminology, methodology & 36 \\
Activities in groups & 33 \\
Bibliographic references - for further professional development & 15 \\
\hline
\end{tabular}

Notes Multiple answers were possible.

level of knowledge' and of a very small percentage at 'Very strong level of knowledge.'

As it can be seen, 36 respondents indicated the specialized literature as the main source of information in their professional life, very close to the legislation and the active participation to the European funded projects (25, respectively 24). Conferences and workshops are also considered valuable sources of information and knowledge (indicated by 21 respondents), given that attending training courses, specific for the public administration, has been limited due to local budget constraints. Seven respondents indicated the Internet as a reliable source of information and learning (table 5).

The results of the questionnaire regarding the training materials and methods and the way of transferring the information, with multiple possibilities was not a surprise (table 6).

If in the previous years the classical training models predominated in the public administration's activity, the respondents indicated that a change of approach is necessary. The debates on specific cases or hypothetical scenarios, multimedia materials, theoretical presentations and group activities are indicated by most respondents, but as the source of information, the bibliographic reference was indicated. 
TABLE 7 Results on Responses Revealing the Appreciation on the Opportunity to Gain Knowledge in the Field of Sustainable Energy Consumption, EE and 1 Climate Change (Agree \& Strongly Agree Responses in Percent)

\begin{tabular}{lr}
\hline Responses & Number \\
\hline Possibility to apply the knowledge acquired in the personal life & 90 \\
Improvement of the professional capacity to operate in processes, & 81 \\
activities and projects in the field & \\
Improvement of the professional skills related to the workplace & 76 \\
\hline
\end{tabular}

TABLE 8 Results on Responses Revealing the Leadership Role in Organizational Learning (Percentage)

\begin{tabular}{lcc}
\hline Responses & $(1)$ & $(2)$ \\
\hline Support and seek learning opportunities for subordinate staff & 67 & 28 \\
$\begin{array}{l}\text { Ensures that the team's actions are in accordance with the values } \\
\text { /vision of the organization: sustainable with low carbon emissions }\end{array}$ & 42 & 29 \\
\hline
\end{tabular}

NOTES Column headings are as follows: (1) very strong and strong agree, (2) agree.

The result of the questionnaire about the opportunity to be trained in the field of sustainability, responsible energy consumption, EE and climate change (table 7) was assessed as positive by most participants. Responses of 'Agree' and 'Very strong agree' were formulated by $76 \%$ of the respondents regarding the training as a form of acquisition of new skills that can be transposed to the current inactivity, $81 \%$ of the respondents consider that the training contributes to the development of the professional capacity with direct implications for the positive influence of community life and 90\% intend to implement this knowledge in private life and share lessons learned with family and friends.

An emphasis was placed in the last part of questionnaire on determining the role of leadership in organizational learning. As shown in table 8 , the paper initiated the first steps to investigate the perception of employees about leadership in terms of supporting and seeking learning opportunities for the public servants, and to know whether the actions taken are consistent with the organization's values and vision - to become an organization and sustainable community with low carbon emissions.

\section{Conclusions}

The present study's objective was to explore the training need for cc and sustainable energy consumption in the case of public LAs. A survey-based on a predefined questionnaire has been used as research methodology. Research results have identified and character- 
ized: the level of actual knowledge and the training needs related to the topics of the investigation, the preferred or frequently sources of professional information and learning, the most relevant training materials and methods that could better support knowledge and information transfer between trainers and trainees and the leadership role in promoting and supporting the culture of learning. The research results are limited to the research sample defined by the respondents' group (public servants and employees of other public organizations). All the respondents appreciated the opportunity to learn and developed their skills in the sustainable energy consumption, energy efficient and climate change fields ( $90 \%$ of the responses were 'Agree \& Strongly Agree'). As a general picture of the respondents (potential trainees) some characteristics have been capitalized through the presented study:

- LA employees expressed a very high training need for water management and cc topics;

- They usually achieve professional information and knowledge (accompanying by a self-learning process) from scientific resources, legislation (including laws, norms and standards) and their activities in projects;

- The most relevant training materials and methods that could accelerate the information and knowledge transfer have been considered: debate on real cases or working on hypothetical scenarios, video presentations of case studies and presentation of concepts, terminology and methodologies followed by group activities (learning, interacting and working);

- The leadership role in (public) organizational learning has been appreciated most on the ways top management offer the 'support and seek learning opportunities for subordinate staff.'

\section{Acknowledgements}

The paper is related to the project: 'Smart and Sustainable Energy Consumption' - Acronym SASEC, e-MS RORS-300, founded with support of the European Commission, through the Interreg IPA Cross-border Cooperation Program Romania-Serbia. This paper and the communication reflect the views only of the authors, and the Commission cannot be held responsible for any use, which may be made of the information contained therein.

\section{References}

Alibašić, H. 2017. 'Measuring the Sustainability Impact in Local Governments Using the Quadruple Bottom Line.' The International Journal of Sustainability Policy and Practice 13 (3): 37-45. 
Dobos, Á. 2014. 'Experiential Learning for Professional Development in the Civil Service.' Procedia: Social and Behavioral Sciences 116:508590.

Draghici, A., G. Fistis, C. Albulescu, and G. Draghici. 2015. 'Research on Training Needs Identification: Leadership in Sustainability.' In Proceedings of the MakeLearn and тім Joint International Conference: Managing Intellectual Capital and Innovation for Sustainable and Inclusive Society, 711-18. Bangkok, Celje, and Lublin: ToKnowPress.

European Commission. 2011. 'A Roadmap for Moving to a Competitive Low Carbon Economy in 2050.' https://ec.europa.eu/clima/sites/ clima/files/strategies/2050/docs/roadmap_2050_ppt_en.pdf

European Commission. 2019. 'Reflection Paper: Towards a Sustainable Europe by 2030.' https://ec.europa.eu/commission/sites/betapolitical/files/rp_sustainable_europe_30-01_en_web.pdf

Guskey, T. R. 2003. 'Analyzing Lists of the Characteristics of Effective Professional Development to Promote Visionary Leadership.' NASSP Bulletin 87 (637): 4-20.

Korthagen, F. 2017. 'Inconvenient Truths about Teacher Learning: Towards Professional Development 3.o.' Teachers and Teaching 23 (4): 387-405.

Noe, R. A., A. D. Clarke, and H. J. Klein. 2014. 'Learning in the TwentyFirst-Century Workplace.' Annual Review of Organizational Psychology and Organizational Behavior 1 (1): 245-75.

Stewart, C. 2014. 'Transforming Professional Development to Professional Learning.' Journal of Adult Education 43 (1): 28-33.

United Nations. 2015. 'Transforming our World: The 2030 Agenda for Sustainable Development.' https://sustainabledevelopment.un.org/ post2015/transformingourworld 